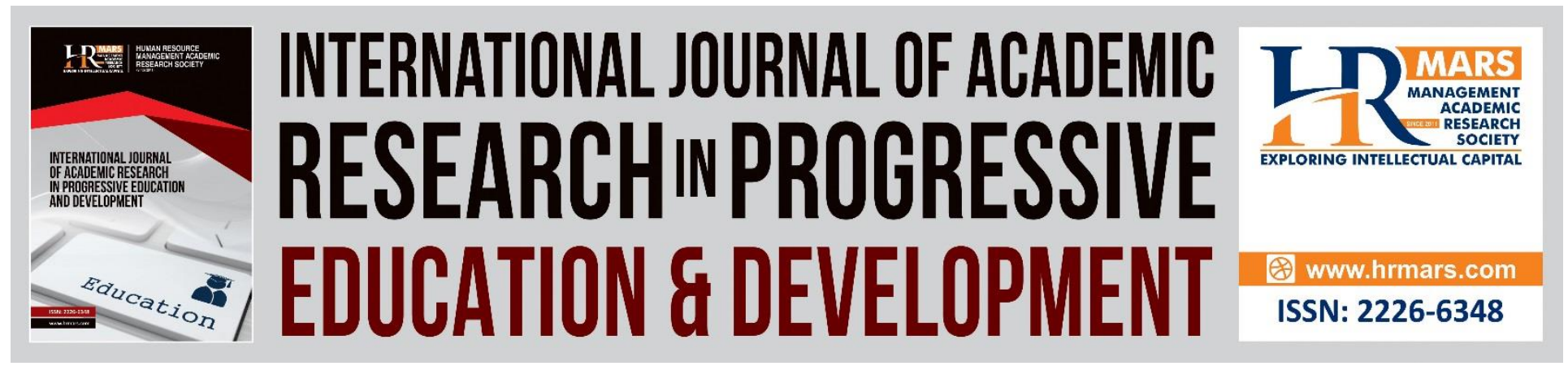

\title{
Young Children's Representations: A Model for Using and Understanding Representations
}

Kamariah Abu Bakar, Suziyani Mohamed, Faridah Yunus

To Link this Article: http://dx.doi.org/10.6007/IJARPED/v8-i4/6782

DOI:10.6007/IJARPED/v8-i4/6782

Received: 10 November 2019, Revised: 30 November 2019, Accepted: 16 December 2019

Published Online: 31 December 2019

In-Text Citation: (Bakar et al., 2019)

To Cite this Article: Bakar, K. A., Mohamed, S., \& Yunus, F. (2019). Young Children's Representations: A Model for Using and Understanding Representations. International Journal of Academic Research in Progressive Education and Development, 8(4), 921-930.

Copyright: (C) 2019 The Author(s)

Published by Human Resource Management Academic Research Society (www.hrmars.com)

This article is published under the Creative Commons Attribution (CC BY 4.0) license. Anyone may reproduce, distribute, translate and create derivative works of this article (for both commercial and non-commercial purposes), subject to full attribution to the original publication and authors. The full terms of this license may be seen

at: http://creativecommons.org/licences/by/4.0/legalcode

Vol. 8(4) 2019, Pg. 921 - 930

http://hrmars.com/index.php/pages/detail/IJARPED

JOURNAL HOMEPAGE

Full Terms \& Conditions of access and use can be found at http://hrmars.com/index.php/pages/detail/publication-ethics 


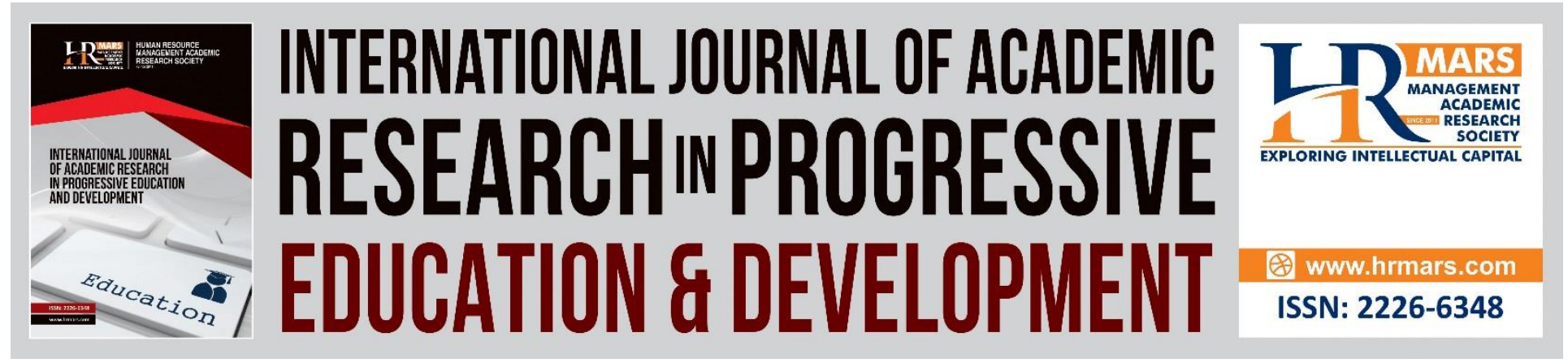

\title{
Young Children's Representations: A Model for Using and Understanding Representations
}

\author{
Kamariah Abu Bakar, Suziyani Mohamed, Faridah Yunus \\ Center of Education and Community Wellbeing, Faculty of Education, Universiti Kebangsaan \\ Malaysia \\ Email: kamariah_abubakar@ukm.edu.my
}

\begin{abstract}
The purpose of this paper is to review the research on representation creation and its usage in classrooms to facilitate mathematical understanding. In the first part, the paper reviews the importance of representation in respect to mathematical learning. Then, a model linking representation usage with understanding is discussed. In conclusion, the paper proposes that learners utilize multiple representations including manipulatives, drawings, verbal and symbol forms in future research in an effort to obtain a congruent picture concerning the mathematical understanding of young children.
\end{abstract}

Keywords: Young Children, Representation, Understanding, Mathematics

\section{Introduction}

There is marked emphasis regarding the role of understanding as being one of the most critical areas involved in the teaching and learning of mathematics. Researchers have highlighted the importance of teaching and learning mathematics by means of understanding (Hiebert, 1997; NCTM, 2000). When students learn mathematics, they should learn by means of understanding it. Learning mathematical concepts by understanding it is considered much more beneficial in comparison to memorizing techniques of facts and formulas. This is because when students learn by the means of understanding, they are building mathematical skills and knowledge that can be elicited when necessary, applied flexibly, adapted to fit new situations, and used to learn and grasp new concepts (Hiebert, 1997). Additionally, when students learn mathematics via the sphere of understanding, confidence in their mathematical ability develops, leading to their eventual engagement in various challenging mathematical activities, tasks and problem-solving exercises (Hiebert, 1997). Teaching and learning mathematics with an emphasis on understanding can aid students in developing and constructing skills which they can actually practice (Hiebert, 1997). An organization made up of mathematics professionals in the United States of America, the National Council of Teachers of Mathematics (NCTM, 2000) and more recently the Common Core State Standards in Mathematics (CCSSM) have reaffirmed the 
importance of learning mathematics via understanding and called for educators to employ effective mathematical instructions that aid the understanding of students (CCSSO \& NGA, 2010). The NCTM Principles and Standards for School Mathematics (PSSSM) state that, "students must learn mathematics with understanding" (NCTM, 2000, p. 11). Similarly, both the Primary and Secondary Mathematics Curriculum in Malaysia advocate teachers to ensure balance between mastering the mathematical knowledge and skills along with conceptual understanding (Ministry of Education Malaysia, 2006). Clearly, the documents and organizations mentioned above indicate the prominence of the promotion of understanding as an important goal in the education of mathematics. Therefore, it is of crucial importance that teachers prepare themselves with effective mathematical approaches and facilitate students in the acquirement of mathematical competencies that is coupled with understanding.

How is the term understanding defined? Too often, the term understanding has been considered the attainment of knowledge and skills (Perkins \& Unger, 1999). Yet, there is no guarantee that students who have knowledge or skills about a topic or concept, fully understand that particular concept. If we take young children who are capable of solving a subtraction problem, for instance, their answers to those questions do not necessarily reflect their understanding of the subtraction concept. This is so because the child might have just memorized the steps and procedures to find the solution to those subtraction problems and yet have no idea as to what the concept of subtraction really means. Taking into account the fact that understanding is not directly observable, it is not always possible for teachers to infer the understanding of students through the representations created and used by the students. Representation denotes any configuration of signs, characters or objects that can also represent something else (Goldin, 1998; Salleh, Jusoh, Embong, \& Mamat, 2018; Kai \& Rahman, 2018). For instance, a photograph can portray a reallife event, a numeral/ number can exhibit certain quantities of objects, a written word can represent a numeral, and a numeral can represent a spoken word.

A large number of studies regarding the usage of representations in mathematics classrooms worldwide have been conducted involving the use of different representational forms. A variety of representation forms comprising diagrams (Diezmann \& English, 2001; Pantziara, Gagatsis, \& Elia, 2009; van Garderen et al., 2013), number lines (Bobis, 2007; Gonsalves \& Krawec, 2014) and pictures (Stohlmann, Yang, Huang, \& Olson, 2019; Woleck, 2001) have been conducted across various mathematical topics (numbers, operations and probability). With the recent advancement in technology, researchers have investigated the potential of technology-based representations to aid mathematical sense making (Bakar \& Karim, 2019; Özmantar, Akkoç, Bingölbali, Demir, \& Ergene (2010), particularly in the support of the learner's visualizations. Researchers involved in these studies assert that students employ representations, as various representations support the students' understanding of mathematical concepts and facilitate problem-solution. Additionally, researchers have highlighted the importance of using different forms of representations and performing translations between representations (Ainsworth, Bibby \& Wood, 2002). 
Despite the large number of studies investigating representation usage in the teaching and learning of mathematics, research involving young children and their use of representations in learning are scarce (Johns, 2015). Researchers have used children's' drawings to gain insights into their exposures, experiences and understanding of various mathematical concepts involving numbers and operations, mass, time and length (Bakar \& Karim, 2019; MacDonald, 2010; MacDonald \& Lowrie, 2011; Smith \& MacDonald, 2009; Thomas, Mulligan, \& Goldin, 2002). Mathematics educators and researchers around the globe have acknowledged the significance of representations in teaching and learning and have indicated that representations facilitate students in the communication and construction of mathematical thinking and ideas (Rosli, Goldsby, \& Capraro, 2015; Ainsworth et. al., 2002; Pape \& Tchoshanov, 2001). Representations can be used as a thinking tool and for the gain of insights as well (Diezmann \& English, 2001). There are a number of means that can be used in the communication of mathematical thinking and understanding through writing, oral forms, the use of pictures, diagrams, and physical and virtual manipulatives. In fact, researchers have highlighted the strong connections between representation and understanding, in which the student's level of understanding is positively connected to the types of representations used (Mokwebu, 2013) and the capability to employ a variety of representation forms. A previous study by Kato, Kamii, Ozaka \& Nagahiro (2002) found that Japanese children (aged 3 to 7 years) were capable of representing the numerals of several groups of objects shown to them. However, when given another task, the majority of children preferred to represent the quantity of objects with drawings despite previous tasks proving that these children were competent in representing objects with numerals. Likewise, (Vandersteen, 2002) reported that children chose to represent the quantity of objects showed to them in this manner as the children consider drawings as more meaningful to them compared to the writing of numerals. The children found that it is more troublesome to link numerals with real-life situations. This provided evidence that the children's ability to represent mathematical symbols does not really embody conceptual understanding, instead it may only exemplify superficial understanding. Furthermore, the children's understanding of numerals and mathematical symbols are fragile (e.g. it may disrupt when additions are performed). For example, when given addition tasks comprising a mixture of dots ( 3 dots) and numerals (2), children are more inclined to add one (for the numeral). Hence they provided the answer of 4 as the total (Moomaw \& Dorsey, 2013).

The representational ability of the student influences his/her problem-solving performance. Students with high representational ability will showcase great performances in respect to problem solving. In contrast, students who have a low ability in creating representations often face difficulties and frequently failed to solve problems (Krawec, 2014). The employment of a particular type of representation form also has a critical function in problem solution as success in problem solving is dependent on the type of representation utilized by the students. van Garderen and Montague (2003) found that students who employed schematic representations to solve posed problems demonstrated a better performance in comparison to their peers who utilized pictorial representations. 
Vol. 8, No. 4, 2019, E-ISSN: 2226-6348 @ 2019 HRMARS

Despite a number of studies investigating 'the representation usage of students, there is a lack of empirical studies that describe the way in which understanding develops as a result of the engagement of young children with multiple representations. Although a number of studies reporting on children's representation creations for learning and problem-solving have been done, the focus was mainly on investigating a particular form of representation. Additionally, previous research focused on the examination of students' representations which was of a limited number. Also, we know little about the children's understanding of the concept introduced as previous research concentrated largely on the achievements of children resulting from representational usage. Despite the fact that these findings afforded valuable evidence pertaining to the link between representation and mathematical learning, they were insufficient in explaining the depth of children's understanding of the mathematical concepts that were taught/being explored. The review of literature surrounding representation and understanding revealed that a large number of researchers have offered to define and categorize understanding. However, the Lesh Translation Model is considered the most suitable as they describe the depth of the student's mathematical understanding across levels and topics when multiple representations are employed

\section{Lesh Translation Model}

Lesh, Post \& Behr (1987) highlighted the importance of both the internal and external representations for understanding mathematical concepts. Understanding is reflected as the ability to represent mathematical ideas in multiple forms, together with the ability to make connections among different representations which Suh, Johnston, Jamieson, and Mills (2008) termed as representational fluency. The use of multiple representations and the ability to translate representational models have been shown to affect the ability of students to construct mathematical ideas and thinking (Chigeza, 2013; Goldin \& Shteingold, 2001; Lamon, 2001) as well as problem-solving (Gagatsis \& Shiakalli, 2004).

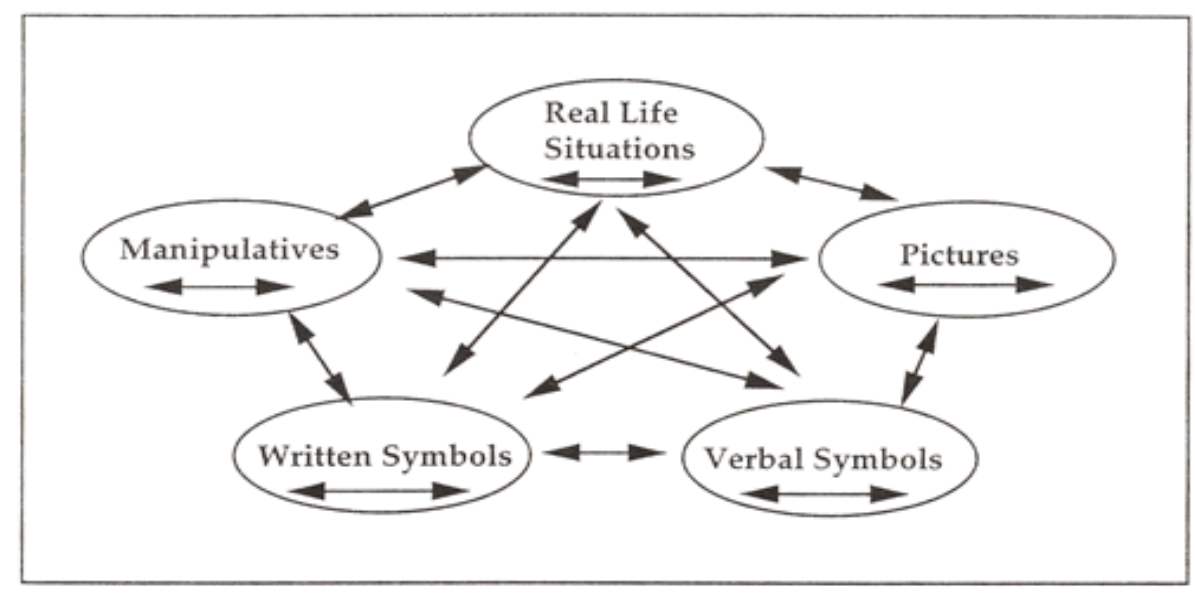

Figure 1. Lesh Translation Model (1987)

The Lesh Translation Model (1987) suggests five modes of representation that can be utilized in the teaching and learning of mathematics: 
Vol. 8, No. 4, 2019, E-ISSN: 2226-6348 @ 2019 HRMARS

i) Real world situations involving real world events.

ii) Manipulatives include physical and virtual manipulatives. Physical manipulatives refer to any concrete objects (e.g. cubes, counters, blocks) that can be pointed to, touched and moved. Recently, with the aid of technological advancement, the manipulation of objects can also be done via the computer screen (virtual manipulatives). In addition to providing similar benefits as with the case of physical manipulatives, the virtual manipulatives offer additional advantages by providing immediate feedback to the users.

iii) Pictures. Pictures or diagrams refer to the images containing mathematical ideas that can be found in various sources such as in textbooks, flashcards, signboards and photographs. Pictures created by children are considered a powerful learning experience because many aspects of mathematical concepts and ideas need to be considered when creating a drawing that mostly occurs with pictures being either pre-drawn by teachers or readily printed in books and papers/ flashcards. 'Pictures' as suggested by the researchers refer to the created pictures by children that include hand-drawn pictures and photographs captured by the children.

iv) Spoken symbols include both formal spoken mathematical language and everyday language that can be used to answer questions and make justifications.

v) Written symbols include both formal and informal printed symbols. It refers to both the mathematical symbols and the written words connected to them. Prior to being introduced to formal symbols (e.g. the numeral ' 5 ' to represent the quantity), children may use informal symbols (e.g. drawing five circles to represent the quantity).

The Lesh Translation Model (1987) recommends the extensive use of various types of representation and the utilizing learner's ability to translate between and within various modes of representation. The arrows refer to the variety of means that can be utilized by the students to obtain access to mathematical ideas and concepts. The arrows positioned inside the circles denote translations made within the same representation form (e.g. pictures in books and pictures on flashcards). On the contrary, the arrows located outside the circles signify translation made between different representation forms (e.g. manipulatives and symbols). Since it may be necessary to use more than one representation form when solving a problem, children are required to have the ability to use multiple representations as well as the capability to translate within and between different representation forms to solve mathematical problems successfully (Lesh et al., 1987). Taking into account the differences children have in terms of knowledge, skills, abilities and learning styles, it is of vital importance that teachers introduce multiple representations to help individuals get the gist of mathematical concepts. Furthermore, researchers claim that the use of multiple representation and translation fluency is associated with problem-solving success (Gagatsis \& Shiakalli, 2004; Lesh et al., 1987).

Children must be able to link one representation to another to enable translation to occur. They begin with any representation form (i.e. the one most meaningful to them) and later use other forms to explore mathematical ideas. For example, children may start with manipulating concrete materials (representing the quantity 5 with cubes) and then switch to using pictures (drawing 5 circles or dots) to exemplify the quantity given. After having enough exposure and experience with concrete and semi-concrete representation forms, they can be introduced to 
mathematical symbols. When more translations occur, more connections are attained which then form a "network of representations". It is the quality and the quantity of connecting different modes of representations that supports problem-solving success. On the other hand, problem-solving may be troublesome when children struggle in performing such translation. Hence, it is imperative that teachers support the children's capabilities to switch between and within different representation forms. Teachers are responsible in providing children with broad exposure and practice using different representation forms along with making translations within and between representations (Ballard, 2000). Encouraging children to generate their own representation of a concept (rather than being given ready-made representations) is one of the means of supporting children in increasing the number of connections made within and between different modes of representation. In addition, children should be given various tasks using multiple representations, as such activities necessitate repeated transitioning between different representations. With enough practice, students will be able to employ multiple representations as a "natural need" to process mathematics (Friedlander \& Tabach, 2001, p. 176). Additionally, fluency to switch within and between representations aid students in attaining deep mathematical understanding along with the retaining of mathematical concepts (Lesh et al., 1987).

Oftentimes, students struggle in employing a particular representation form. In fact, there are students who favor a specific form of representation. Hence, employing various forms of representation may help tackle such troubles and preferences. For instance, when students struggle in using a particular form (one that is required to be used) to solve a posed task, they may alternate and use another representation form. Also, substituting a particular form with another representation form is required when students get stuck in the finding of solutions. Additionally, it is beneficial for students to translate from one representation to another to help them comprehend a concept. By doing so, the students demonstrate their efforts in expanding their current understanding (Pirie \& Kieren, 1994). Most importantly, the students' comprehension of the concepts increases as a result of performing translation between and within representation forms.

\section{Conclusion and Recommendation}

This article reviewed the importance of representation for mathematical learning and recommends the use of the Lesh Translation Model as a framework to record the understanding of mathematical concepts of children as they consist of the use of multiple representations that assist in understanding. This study will have implications for representational formation and usage in both instruction and practice in early childhood mathematics classrooms. Employing a variety of representation forms to convey mathematical thinking and concepts will provide insights into the development of mathematical conceptual understanding. In addition, examining the function of a variety of representation forms will extend upon and elaborate on the current translation model (Lesh, Post, \& Behr, 1987). Exploring the flexibility in using multiple representations, as well as the facilitation in terms of performing a translation will shed light on the use of representation in the development of the understanding of children. Such knowledge and information may in turn contribute additional data to the literature predominantly pertaining to the deep understanding of mathematical concepts of that of young children. 
Vol. 8, No. 4, 2019, E-ISSN: 2226-6348 ㄷ 2019 HRMARS

Moreover, previous research has used this model to examine the understanding of participants involving older students. By using this model to investigate participants comprised of young children, it may permit the simultaneous examination in respect to the usage of representations and understanding facilitating the emphasis on important aspects of representation usage that have positive links to conceptual attainment and understanding.

\section{Acknowledgment}

This research was supported by grants provided by the Faculty of Education, Universiti Kebangsaan Malaysia (GG-2019-003) and (GG-2019-061).

\section{References}

Ainsworth, S., Bibby, P., \& Wood, D. (2002). Examining the effects of different multiple representational systems in learning primary mathematics. The Journal of the Learning Sciences, 11(1), 25-61.

Bakar, K. A., \& Karim, A. A. (2019). Young Children's Photographs of Addition in the School Environment. International Journal of Academic Research in Business and Social Sciences, 9(8), 1-14.

Ballard, J. W. (2000). Students' use of multiple representations in mathematical problem solving. Unpublished PhD dissertation, Montana State University, Bozeman, Montana.

Bobis, J. (2007). The empty number line: A useful tool or just another procedure? Teaching Children Mathematics, 13(8), 410-413.

Chigeza, P. (2013). Translating between and within representations: Mathematics as lived experiences and interactions. Paper presented at the Annual Meeting of the Mathematics Education Research Group of Australasia (MERGA, 36th, Melbourne, Victoria, Australia, 2013).

Council of Chief State School Officers \& National Governers Association Center for Best Practices. (2010). Common Core State Standards for Mathematics.

Diezmann, C., \& English, L. (2001). The Roles of Representation in School Mathematics: 2001 YearBook (pp. 1-23). Virginia: NCTM.

Friedlander, A., \& Tabach, M. (2001). Promoting multiple representations in algebra. In A. Cuoco (Ed.), The roles of representation in school mathematics (pp. 173-184). Reston, VA: NCTM.

Gagatsis, A., \& Shiakalli, M. (2004). Ability to translate from one representation of the Concept of function to another and mathematical problem solving. Educational Psychology, 24(5), 645-657. doi: 10.1080/0144341042000262953

Gonsalves, N., \& Krawec, J. (2014). Using number lines to solve Math word problems: A strategy for students with learning disabilities. Learning Disabilities Research \& Practice, 29(4), 160-170.

Goldin, G. (1998). Representational systems, learning, and problem solving in mathematics. Journal of Mathematical Behavior, 17(2), 137-165. doi: 10.1016/S0364-0213(99)80056-1

Goldin, G., \& Shteingold, N. (2001). Systems of representations and the development of mathematical concepts. In A.A. Cuoco \& F.R. Curcio (Eds.), The roles of representation in school mathematics (pp 1-23). Reston, VA: NCTM 
Hiebert, J. (1997). Making sense: teaching and learning mathematics with understanding. Portsmouth, NH: Heinemann.

Johns, K. (2015). How do kindergarteners express their mathematics understanding? Universal Journal of Educational Research 3(12),1015-1023.

Kato, Y., Kamii, C., Ozaki, K., \& Nagahiro, M. (2002). Young children's representations of groups of objects: The relationship between abstraction and representation. Journal for Research in Mathematics Education, 33(1), 30-45.

Krawec, J. L. (2014). Problem representation and mathematical problem solving of students of varying math ability. Journal of Learning Disabilities, 47(2), 103-115.

Lesh, R., Post, T., \& Behr, M. (1987). Representations and translations among representations in mathematics learning and problem solving. In C.Janvier (Ed.), Problems of representation in the teaching and learning of mathematics (pp. 33-40). Hillsdale, NJ: Erlbaum.

MacDonald, A. (2010). Heavy thinking: Young children's theorising about mass. Australian Primary Mathematics Classroom, 15(4), 4-8.

MacDonald, A., \& Lowrie, T. (2011). Developing measurement concepts within context: Children's representations of length. Mathematics Education Research Journal, 23(1), 2742. doi: 10.1007/s13394-011-0002-7

Ministry of Education Malaysia. (2006). Integrated Curriculum for Primary Schools, Curriculum Development Centre.

Mokwebu, D. J. (2013). An exploration of the growth in mathematical understanding of grade 10 learners. University of Limpopo, Turfloop Campus.

Moomaw, S., \& Dorsey, A. G. (2013). The Use of Numeric and Non-Numeric Symbols by Preschool Children in Early Addition. Journal of Research in Childhood Education, 27(3), 319-329.

NCTM. (2000). National Council of Teachers of Mathematics, Principles and standards for school mathematics. Reston, VA: National Council of Teachers of Mathematics.

Özmantar, M. F., Akkoç, H., Bingölbali, E., Demir, S., \& Ergene, B. (2010). Pre-Service Mathematics Teachers' Use of Multiple Representations in Technology-Rich Environments. Eurasia Journal of Mathematics, Science \& Technology Education, 6(1).

Pantziara, M., Gagatsis, A., \& Elia, I. (2009). Using diagrams as tools for the solution of nonroutine mathematical problems. Educational Studies in Mathematics, 72(1), 39-60.

Pape, S. J., \& Tchoshanov, M. A. (2001). The role of representation (s) in developing mathematical understanding. Theory into Practice, 40(2), 118-127.

Perkins, D. N., \& Unger, C. (1999). Teaching and learning for understanding. Instructional-design theories and models: A new paradigm of instructional theory, 2, 91-114.

Pirie, S., \& Kieren, T. (1994). Growth in mathematical understanding: how can we characterise it and how can we represent it? Educational Studies in Mathematics, 26(2-3), 165-190.

Rosli, R., Goldsby, D., \& Capraro, M. M. (2015). Using Manipulatives in Solving and Posing Mathematical Problems. Creative Education, 6(16), 1718.

Smith, T., \& MacDonald, A. (2009). Time for talk: The drawing-telling process. Australian Primary Mathematics Classroom, 14(3), 21-26.

Stohlmann, M., Yang, Y., Huang, X., \& Olson, T. (2019). Fourth to Sixth Grade Teachers' Invented 
Real World Problems and Pictorial Representations for Fraction Division. International Electronic Journal of Mathematics Education, 15(1), em0557.

Suh, J., Johnston, C., Jamieson, S., \& Mills, M. (2008). Promoting decimal number sense and representational fluency. Mathematics Teaching in the Middle School, 14(1), 44-50.

Salleh, M., Jusoh, A., Embong, R., \& Mamat, M. (2018). Learning Organizational Model in the 21th Century Classroom at Sultan Mahmud Science Secondary School in Terengganu, Malaysia. International Journal of Academic Research in Progressive Education and Development, 7(4), 410-426.

Kai, D. K., Rahman, B. A. I. (2018). The Impact of Financial Indicators towards Stock Returns of Finance Companies Listed on Bursa Malaysia, International Journal of Academic Research in Accounting, Finance and Management Sciences 8 (3): 128-140.

Thomas, N. D., Mulligan, J. T., \& Goldin, G. A. (2002). Children's representation and structural development of the counting sequence 1-100. Journal of Mathematical Behavior, 21(1), 117-133. doi: 10.1016/S0732-3123(02)00106-2

Garderen, V. D., \& Montague, M. (2003). Visual-spatial representation, mathematical problem solving, and students of varying abilities. Learning Disabilities Research \& Practice, 18(4), 246-254.

Garderen, V. D., Scheuermann, A., \& Jackson, C. (2013). Examining how students with diverse abilities use diagrams to solve mathematics word problems. Learning Disability Quarterly, 36(3), 145-160.

Vandersteen, G. (2002). Children's Own Methods of Recording Number:" I Will Do Two Writings". Mathematics in School, 2-8.

Woleck, K. (2001). Listen to their pictures: An investigation of children's mathematical drawings. In A. A. Cuoco \& F. R. Curcio (Eds.), The roles of representation in school mathematics (pp. 215-227). Reston,VA: The National Council of Teachers of Mathematics. 